\title{
Features of mechanical scanning probe lithography on graphene oxide and $\mathrm{As}(\mathrm{Ge})$ Se chalcogenide resist
}

\author{
P.M. Lytvyn ${ }^{1}$, S.V. Malyuta ${ }^{2}$, I.Z. Indutnyi ${ }^{1}$, A.A. Efremov ${ }^{1}$, O.V. Slobodyan ${ }^{2}$, V.I. Min'ko' ${ }^{1}$ A.N. Nazarov ${ }^{2}$, \\ O.V. Borysov ${ }^{2}$, I.V. Prokopenko ${ }^{1}$ \\ ${ }^{1}$ V. Lashkaryov Institute of Semiconductor Physics, NAS of Ukraine, 41, prospect Nauky, 03680 Kyiv, Ukraine, \\ E-mail: plyt@isp.kiev.ua \\ ${ }^{2}$ National Technical University of Ukraine “Igor Sikorsky KPI”, 37, prospect Peremohy, 03056 Kyiv, Ukraine, \\ E-mail: serhiy.malyuta@gmail.com
}

\begin{abstract}
Combined mechanical scanning probe lithography (SPL) approach applied for the direct mask-less modification of graphene oxide (GO) flakes and the mask patterns engraving in layers of chalcogenide resist with a nanometer scale resolution have been implemented in this work. It was compared the dynamics of mechanical modification of chalcogenide films and multilayer GO flakes deposited from an aqueous suspension. The double-layer $\mathrm{As}_{40} \mathrm{Se}_{60} / \mathrm{As}_{4} \mathrm{Ge}_{30} \mathrm{~S}_{66}$ chalcogenide resist developed for mechanical SPL and pattern formation processes have optimized. The resist with the thickness close to $100 \mathrm{~nm}$ provides formation of minimal pattern elements with the size of several tens nanometers. The SPL approach was realized on the basis of serial NanoScope IIIa Dimension $3000^{\mathrm{TM}}$ scanning probe microscope, and original software utilities were developed. These mechanical SPL could be intended for the verification of innovative ideas in academic researches, the laboratory-level device prototyping, developing the functional prototypes of new devices in bio/nanosensorics, plasmonics, 2D electronics and other modern technology branches.
\end{abstract}

Keywords: mechanical scanning probe lithography, graphene oxide, chalcogenide semiconductor glass, atomic force microscopy.

doi: https://doi.org/10.15407/spqeo21.02.152

PACS 81.16.Nd

Manuscript received 02.04.18; revised version received 12.06.18; accepted for publication 27.06.18; published online 03.07.18.

\section{Introduction}

Since the first scanning probe microscope (SPM) [1, 2] was introduced in the 1980s, it became clear a great potential of SPM for the direct surface modification [3-5] apart of versatile diagnostics of surface physical properties. Application of SPM for nano-lithography, nano-manipulations [6, 7] and nano-preparations [8] is not limited by the type of material (mineral, organic, biological) or environment (ambient, vacuum, liquid) or type of physical interactions (mechanical, electrical, magnetic, thermal, chemical) [9-13]. Depending on the hardware implementation, SPM could be effective starting from the atomic level surface modification up to the surface patterning over hundred microns areas. Unlike to other lithography methods, the SPL resolution limits determined by the technical realization mainly, but not physical limitation, such as diffusion or diffraction effects, for example. Unfortunately, over the past few decades, implementation of SPL into the mass production technologies were failed [14]. The small size of stamps and time-consuming patterning process are major deterrents. For example, the speed of patterning about $10^{12} \mu \mathrm{m}^{2} / \mathrm{h}$ is considered to be a technological standard in semiconductor manufacturing. Currently, the thermal multi-probe SPL provides comparatively high recording rates of $10^{5} \ldots 10^{8} \mu \mathrm{m}^{2} / \mathrm{h}$ [15], but it is still inferior to technology based on extreme ultraviolet. However, SPL stands as unchallenged leader in the field of the laboratory, academic research, where the main principle is to test ideas and develop functional prototypes. Here, these features of SPL come to the fore as the continuous feedback control in drawing the patterns, the possibility of adjusting the templates directly in the process of recording, direct and multi-stage recording (using resists and precursors), the possibility of combining in one sample different physical principles of patterning and various materials (bulk materials, films and 2D materials) [16-19]. Additional abilities are open, namely: 3D printing by SPL, where the tip "condenses" material from the environment [20] and 4D printing, where the extra dimension could be realized using chemical selectivity [21]. 
The most accessible for tasks of rapid prototyping is mechanical SPL, where the SPM tip works like an engraver, cutting surface with a given depth. Features of the mechanical tip-surface interactions under engraving process we analyzed in [22]. There, an example of molecular electronics device prototype structure, produced by mechanical SPL was shown as well. Polymetene nanowires of a given configuration and the cross-section of $3 \times 20 \mathrm{~nm}$ were successfully formed in a multi-layer polytetrafluoroethylene/gold/silicon nanostructure. The task of 2D materials modification, including graphene and graphene oxide, deposited from dispersed solution as separate flakes of arbitrary shapes, is more difficult. Such suspensions are much cheaper than sheet materials deposited on substrates, but operations with separate flakes require a combination of microscopy and lithography techniques. In addition, for these 2D materials, there is an often problem in application of mask lithography because of the high probability of damage of flakes with a thickness in one or more mono-layers. Therefore, SPL is a perfect tool for prototyping of device structures using $2 \mathrm{D}$ materials in academic research.

The aim of this work was to evaluate the possibility of combined mask-less SPL of GO flakes and near simultaneous SPL patterning of chalcogenide resist mask layers. This task is actual for research of GO sensory properties [23, 24] and their modifications by ordered arrays of specified size defects. Amorphous AsSe based semiconductor chalcogenide glasses (ChG) have a number of properties that allow their applications as positive and negative optical and electronic resists as well as for direct relief formation due to photo-fluidity and mass-transport phenomena $[25,26]$. We have shown their unique sensitivity for localized plasmon fields and perspectives of plasmon-assisted nanolithography, a near-field nanoimaging [27] as well as to plasmonic structures productions [28]. Thus, using ChG as a nanolithography mask material provides opportunities for a combination of different types of lithographic patterning.

\section{Materials and methods}

The surface topography and peculiarities of elastic and plastic surface deformation under the SPM tip apex were studied by scanning probe microscope NanoScope IIIa Dimension $3000^{\mathrm{TM}}$ operated in atomic force microscopy (AFM) and force spectroscopy (FS) modes. The NanoLithography package, where the fully C-capable NanoScript $^{\mathrm{TM}}$ language extension included [29], was used for mechanical SPL. The NanoScript ${ }^{\mathrm{TM}}$ extension includes over 200 library functions for programming microscope operation. Surface topography mapping and mechanical SPL were carried out using the TESP silicon tips (Bruker Inc.) [30] with the apex radius 8 to $12 \mathrm{~nm}$ and the cone angle close to $22^{\circ}$. These tips provide controllable loading forces ranged within 1 to $32 \mu \mathrm{N}$ having the cantilever spring constant of $42 \mathrm{~N} / \mathrm{m}$. The shape of tip and range of loading forces provide good conditions for surface engraving/cutting. Note, the silicon-nitride or diamond tips are usually used for mechanical SPL. We compared trenches formed by various tips on a thin gold film in [22]. It was shown that the silicon tips engrave trenches of the best quality (the most narrow and with minimal pile-ups), but they are the most fragile and could be destroyed or contaminated.

The SPL patterning process defined by sequences of commands describing horizontal and vertical movements of SPM scanner encoded into dynamic link libraries files. These files interpreted by SPM software in a proper way. To generate code, we have developed the original Tool Box in the MATLAB environment and created a standalone C\# (c-sharp) Windows utility. Raster or vector image patterns could be easily converted into machine codes perceived by the $\mathrm{C}++$ compiler. The mainly used NanoScripts commands are a vertical movement of the scanner "LithoMoveZ(depth, z_rate)", where "depth" is an absolute movement along the $Z$ axis, "z_rate" is a vertical speed of scanner and "LithoTranslate(x_size, y_size, rate)" that describes the translation of the scanner along $\mathrm{X}, \mathrm{Y}$ axes. Here "X_size" and "y_size" are the absolute movements along $\mathrm{X}$ and $\mathrm{Y}$ axes, respectively. The implemented approach allows a quick encoding of images of any difficulty level with a high resolution, as well as a prompt adjustment of code for compensations of possible hardware distortions and for improvement purposes.

GO was synthesized by Hummers' method [31, 32] and transferred to the water solution. The dispersion was drop-casted using a micropipette onto $\mathrm{Ni}(1 \mu \mathrm{m}) / \mathrm{Si}$ structures, where $\mathrm{Ni}$ film was deposited using the DC magnetron sputtering method. The $\mathrm{ChG}$ films were deposited using the thermal evaporation method in vacuum [33]. Nanolithography was carried out using both single-layer films based on $\mathrm{As}_{40} \mathrm{Se}_{60}$, and doublelayer structures. The first bottom layer was formed with the thickness close to $100 \mathrm{~nm}$ of the $\mathrm{As}_{4} \mathrm{Ge}_{30} \mathrm{~S}_{66}$ compound and the second layer of the 10-nm thickness was formed by $\mathrm{As}_{40} \mathrm{Ae}_{60} \mathrm{ChG}$ compound. These $\mathrm{ChG}$ layers differ in hardness and are etched by different etchants. The double-layer structure of resist allows mechanical patterning of the upper, soft $\mathrm{ChG}$ layer using the ultra-sharp silicon AFM tip. This pattern is transferred through an entire thickness of lower ChG layer by using the methods of chemical etching, forming a mask. The bottom $\mathrm{As}_{4} \mathrm{Ge}_{30} \mathrm{~S}_{66}$ layers were etched in the weak (near $0.05 \%$ ) water solution of $\mathrm{KOH}$. The amorphous structure of $\mathrm{ChG}$ layers provides a high resolution of SPL.

\section{Results and discussion}

It is important to know behavior of the material under SPM tip at mechanical SPL as well as the resistance of the tip to contamination and mechanical damage. We produced matrixes of holes in the $\mathrm{As}_{40} \mathrm{Se}_{60}$ films (100 nm thick) and GO flakes (10 nm thick) deposited on a nickel film (thickness $1000 \mathrm{~nm}$ ). A set of corresponding forcedistance curves was recorded to reveal features of tipsurface interaction. Essentially, this is an analog of 


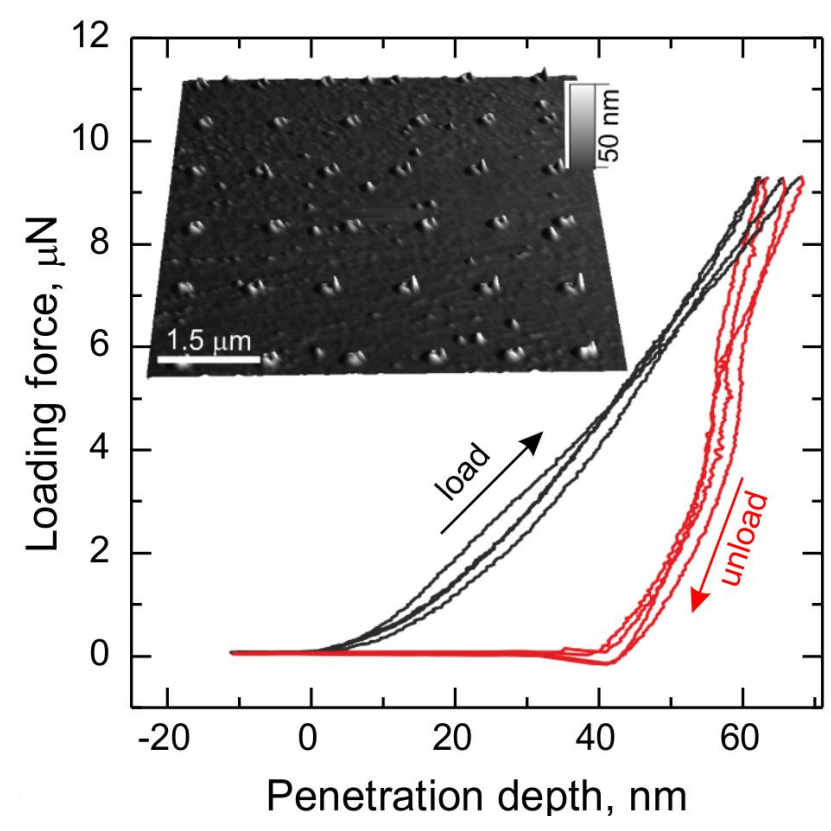

Fig. 1. Force-penetration curves recorded for the AsSe film engraved. Insert shows 3D AFM image of $6 \times 6$ matrix of holes.

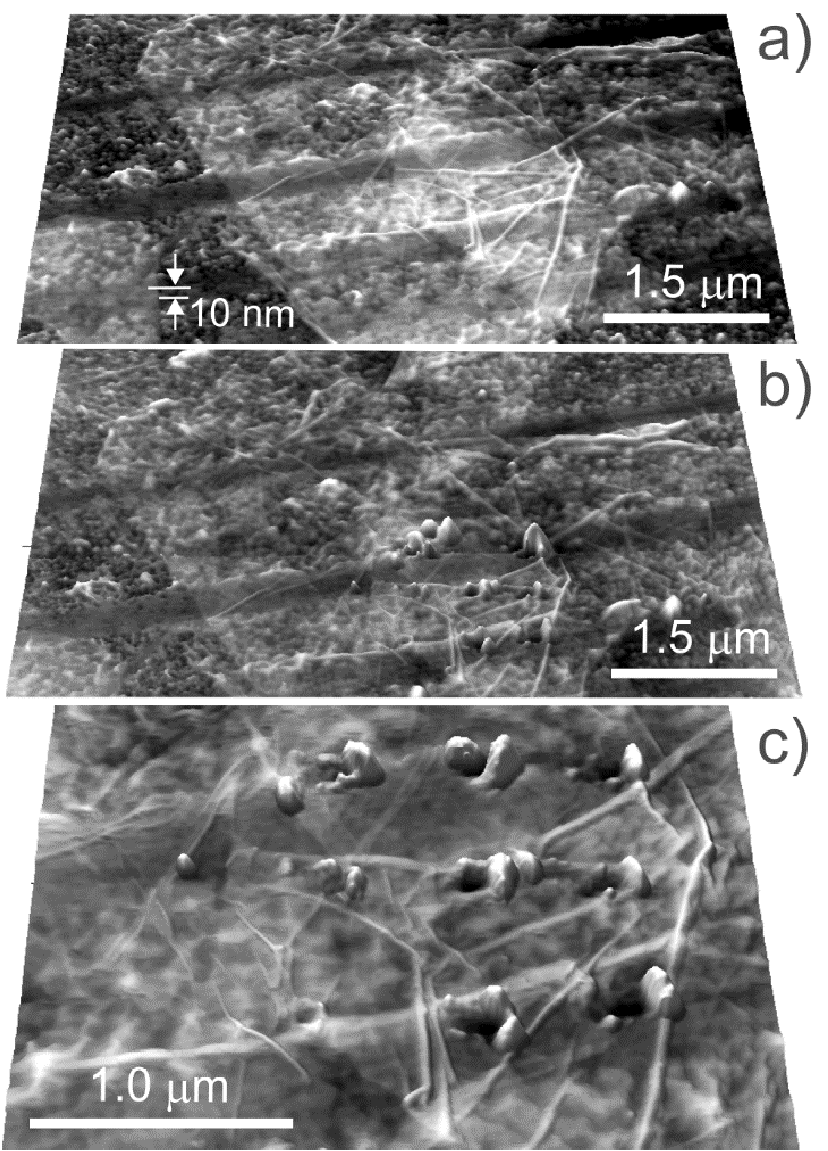

Fig. 2. AFM images of GO flakes on Ni film before engraving the matrix of holes (a) and with the matrix of holes (b). The enlarged fragment is shown in (c).

nanoindentation implemented by means of AFM force spectroscopy. The force-distance curves were converted into the form of Oliver-Farr force-penetration (indentation) curves [34-36] for the convenience of analysis. The example of resulting $6 \times 6$ hole matrix in the $\mathrm{As}_{40} \mathrm{Se}_{60}$ film is shown in the inset of Fig. 1. Dozens of identical holes cover the surface, indicating that there is no change in shape or contamination of the silicon tip during the engraving process. Indentation curves are also well reproduced (Fig. 1). It can be seen from the curves that a smooth elastic-plastic deformation of the surface occurs when a loading force increases, and at the loading of $9.3 \mu \mathrm{N}$ the probe penetrates into the surface to the depth of about $60 \mathrm{~nm}$. When the load decreases, the surface partially relaxes and the residual depth of indent reduces to the value of $44 \mathrm{~nm}$. Negative force values on the unload curve correspond to the resultant adhesive forces that need to be overcome to detach the AFM probe from the surface. The hardness and the reduced elastic modulus of the film could be estimated from the forcepenetration data. The corresponding values are $380 \mathrm{MPa}$ and $16 \mathrm{GPa}$. The obtained values correlate with the values of $630 \mathrm{MPa}$ and $28 \mathrm{GPa}$ obtained by the Nanoindenter II (MTS Systems) with a Berkovich diamond indenter for the films manufactured under identical technological conditions [37]. Note, we used ultra-sharp AFM tip for engraving/cutting the surface, and it is much sharper in its shape as compared to the Berkovich indenter. That is why, the absolute values are expectedly lower.

The GO flakes in their initial state and those with holes engraved are shown in Fig. 2. The sample surface is nonhomogeneous in comparison with $\mathrm{ChG}$ film. There are both heterogeneities of the nickel film (granular structure, linear microdefects) and folded wrinkles of the GO flakes. Three GO flakes are clearly visible in the overview image (Fig. 2a): small size flake at the leftbottom corner, large flake in the central part and small flake lying on the central flake. The thickness of flakes is about $10 \mathrm{~nm}$, which, taking into account the thickness of one GO layer $(0.7-0.8 \mathrm{~nm})$, corresponds to $12-14$ monolayers in the stack. The area with overlapping GO flakes was selected for engraving the holes. The total thickness of overlapping GO flakes made it possible to reduce the influence of nickel substrate in the AFM spectroscopy data. Fig. 2c shows the holes spaced by $700 \mathrm{~nm}$ from each other. The edges of holes are clear, without breaks of the GO flake, and there are pile-ups of extruded material around them.

The force-penetration curves (Fig. 3) are more complicated than in the case of $\mathrm{ChG}$ and reflect the specificity of the sample, which consists of a laminated GO that is not rigidly bound to the substrate, and some influence of the metal film at a large penetration depth takes place. Thus, the curve 1 in Fig. 3a shows a totally elastic nature of the AFM tip interaction with a GO flake at the loading force below $8.2 \mu \mathrm{N}$. The loading and unloading curves coincide and there is no indent at the point of the tip-surface contact. If the load is increased (curve 2), an elastic-plastic region appears with characteristic series of slipping ("breaches") of the tip into the GO depth. The unloading curve indicates formation of the indent of about $70 \mathrm{~nm}$ in depth, as well as the oscillations of the tip-surface interaction force in 

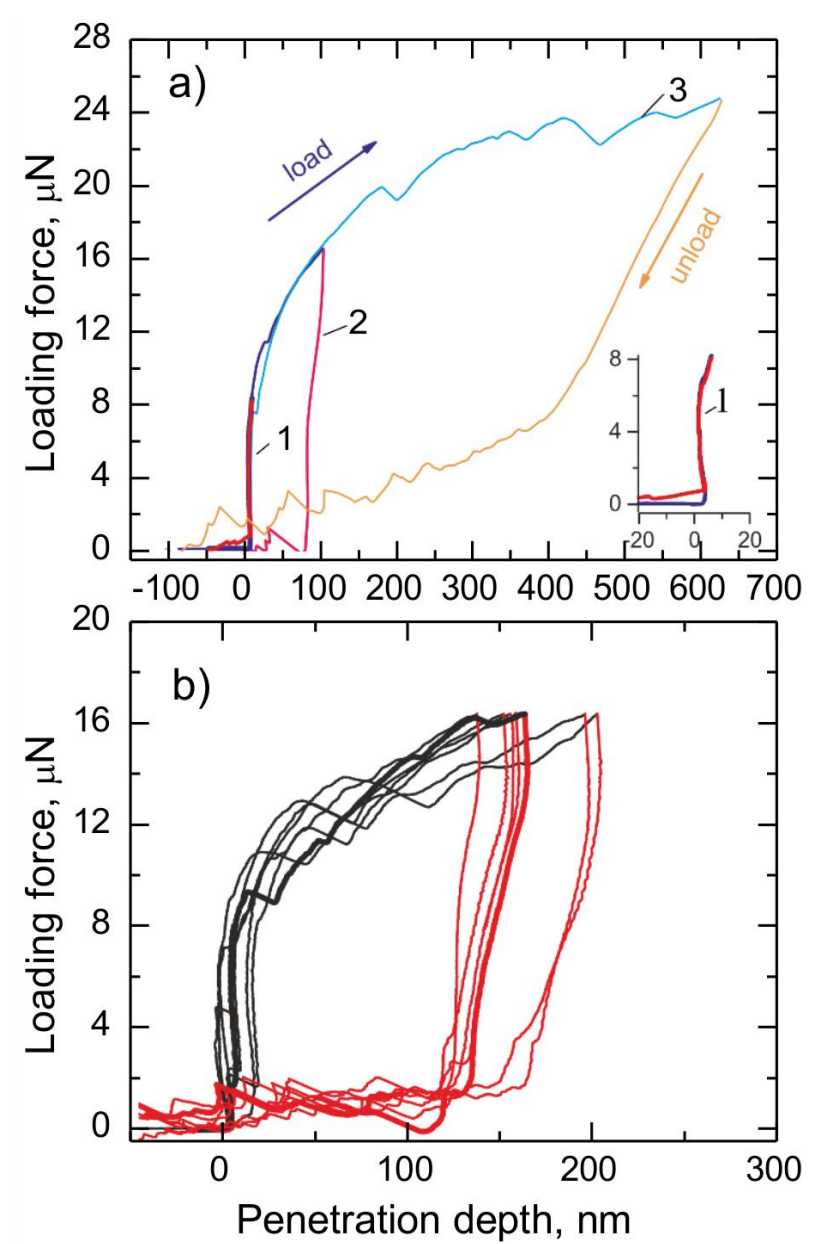

Fig. 3. Force-penetration curves recorded for engraved the hole matrix in GO flakes at the 8,16 and $24 \mu \mathrm{N}$ loading forces (curves 1, 2 and 3, correspondingly) (a). The series of forcepenetration curves collected with the spacing $700 \mathrm{~nm}$ over the surface at $16 \mu \mathrm{N}(b)$.

the detachment region. This is probably due to adhesive interactions involving fragments of the GO flake, which can oscillate in the vertical direction without being bound to the substrate. The tip penetrates deeply into the nickel film, impressing ("riveting") fragments of GO flake in the point of contact at significant increasing the loading force (up to $24 \mu \mathrm{N}$ ). Some pile-ups of nickel films and GO appear around indents.

The matrix of holes in GO (Fig. 2c) was produced at the maximal load of $16 \mu \mathrm{N}$. The corresponding curves are shown in Fig. 3b. The curves are worse reproduced in different points of the surface as compared to the GhS film. Slips ("breaches") into the depths of GO are recorded in different points of the loading curves, but, at the forces exceeding $8 \mu \mathrm{N}$. It is obvious that the observed nature of force-penetration curves defined by the large value of GO Young's modulus (200 to $1000 \mathrm{GPa}$; see, for example, [38]) and a fracture strength as well as by the layered structure of GO. Therefore, elastic behavior of the sample at low loads is quite natural, despite the use of ultra-sharp tip.

Therefore, both of the above described materials are suitable for a mechanical SPL in the configuration chosen, but in the case of GO flakes it is worth, considering the possibility of fixing them to the surface (at least mechanical "riveting") and also improving the homogeneity of the substrate.

The test engraving of relatively large size patterns by mechanical SPL (Fig. 4) has shown acceptable quality in the case of $\mathrm{ChG}$ films. The patterns are transferred in accordance with the dimensions and shapes. Depending on the complexity of pattern and the recording order of its details, there was a need for some software correction of drift for the microscope scanner. The trenches of 90$\mathrm{nm}$ width with a symmetrical pile-ups of about 70-nm width were formed at the given load. The depth of trenches and the height of pile-ups were about $20 \mathrm{~nm}$ over the whole area of the pattern. Engraving was also applied to the GO flakes (for example, A letter, inset in Fig. 4), but the heterogeneities of the substrate prevented to form the qualitative trenches. At the same time, cutting the GO flakes of $~ 10-n m$ thickness at given points of the surfaces is quite effective.

The pile-ups on the ChG film became a problem, if details of pattern are commensurate with the width of the trench. Fig. 5 shows the AFM image of $4.0 \times 5.7 \mu \mathrm{m} \mathrm{SPL}$ pattern containing letters of $350 \mathrm{~nm}$ in their height. Pileups at edges of letters are too large and cannot be effectively removed by chemical treatment, despite the reduced depth of trenches. The mask thickness of $10 \ldots 30 \mathrm{~nm}$, which is defined by the geometry of tip apex, and, respectively, by the width-to-depth ratio of trenches is not sufficient for application in the processing.

To overcome this limitation, the double-layered resist based on ChG films was used. The upper thin soft layer serves to form the initial mask by mechanical SPL. The initial mask was developed further through a total thickness of a lower thick layer of resist by wet chemical etching. This thick layer could be used as a working mask in the technological processes. We have found a combination of materials of the upper and lower layers, differing in mechanical hardness and in selective sensitivity to liquid etchants. The $\mathrm{ChG} \mathrm{As}_{4} \mathrm{Ge}_{30} \mathrm{~S}_{66}$ compound was selected as the material for the 100-nm thick main mask. The $\mathrm{As}_{40} \mathrm{Se}_{60}$ compound was chosen for the material of top layer for patterns engraving. Fig. 6a shows series of trenches with the width varying from 60

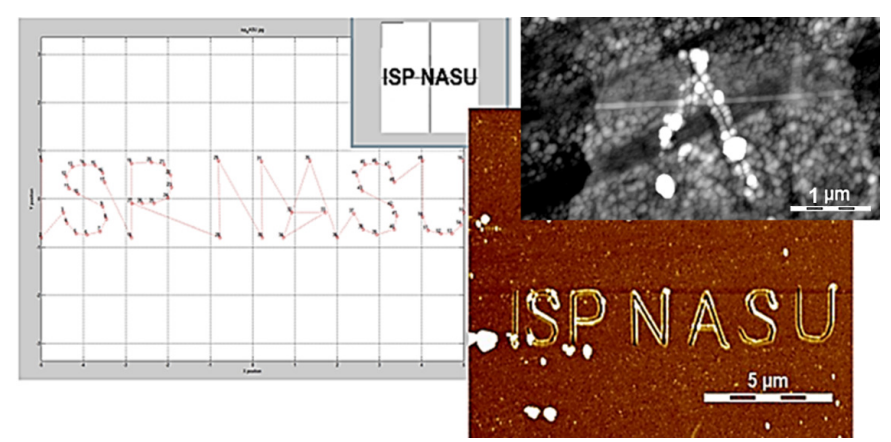

Fig. 4. Software window for SPL pattern definition and examples of letters engraved on GO flake (top) and ChG film (bottom). 


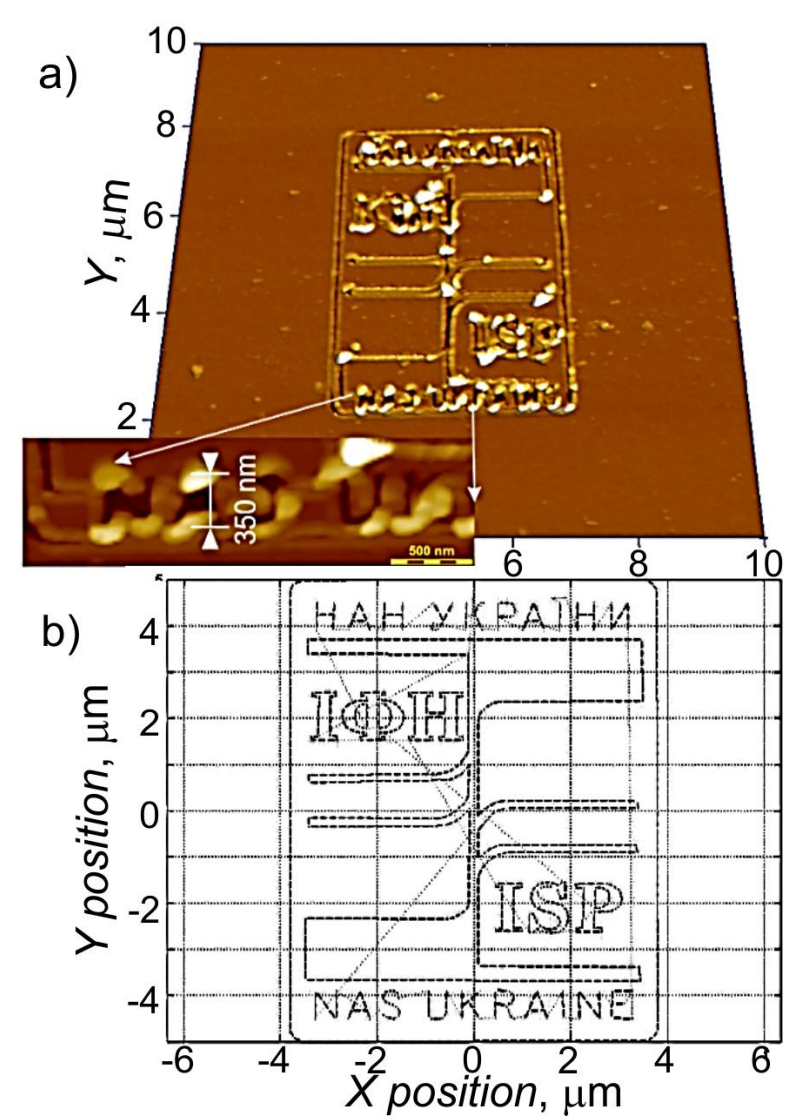

Fig. 5. AFM image of logo engraved on $\mathrm{ChG}$ film by using mechanical SPL (a). The height of letters equals to $350 \mathrm{~nm}$. The encoded pattern (b).

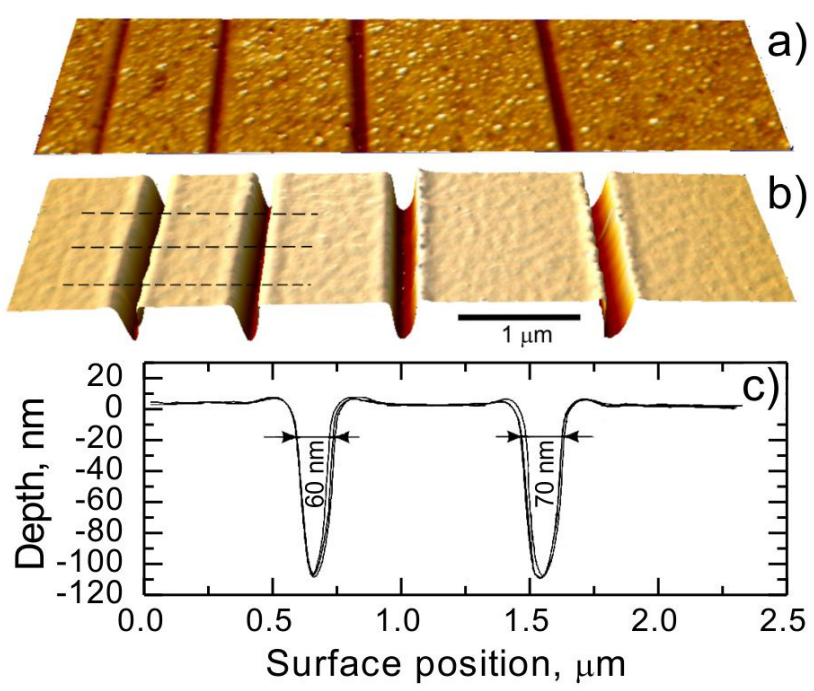

Fig. 6. The mechanical SPL test of double-layered ChG resist: trenches of various width engraved in the top layer of resist (a); the same trenches after wet etching (b); profiles of trenches along the marked lines (c).

up to $90 \mathrm{~nm}$, formed by SPL in the 10 -nm thick $\mathrm{As}_{40} \mathrm{Se}_{60}$ top layer. The width of the trench is defined by the depth of tip penetration into the resist. Since the $\mathrm{As}_{4} \mathrm{Ge}_{30} \mathrm{~S}_{66}$ layer is harder than the top $\mathrm{As}_{40} \mathrm{Se}_{60}$ layer, the loop-back control of loading force magnitude could be included in NanoScript code to keep AFM tip at the boundary of $\mathrm{ChG}$ layers. It can be seen from the figure that the pile- ups of material at the edges are practically absent even at the widest trenches. The result of etching of the same trenches is shown in Figs. $6 \mathrm{~b}$ and $6 \mathrm{c}$. It can be seen that the $\mathrm{As}_{4} \mathrm{Ge}_{30} \mathrm{~S}_{66}$ layer is etched through the total thickness. Variation of the trench width with depth is small (taking into account the pyramidal shape of the AFM tip apex, which is superimposed with the actual profile of the trenches) and pile-ups at the edges of trenches do not exceed $5 \mathrm{~nm}$ in height. Since the trench width of $60 \mathrm{~nm}$ is easily etched over the entire thickness of the lower resist, even with a some lateral erosion (final width equals to $70 \mathrm{~nm}$ ), it is quite possible to control formation of trenches with the width 10 to $20 \mathrm{~nm}$, if parameters of SPL and etching are optimized. That is, the masks of nanometer-sized features could be produced in the double-layer resist by mechanical SPL suitable for application in conventional technological processes.

\section{Conclusions}

The paper describes practical application of mechanical scanning probe lithography technique for the mask-less modification of 2D materials and formation of highresolution masks based on chalcogenide films. It is shown that conventional tapping mode silicon tips (nominal apex radius of $10 \mathrm{~nm}$, cantilever spring constant $42 \mathrm{~N} / \mathrm{m}$ ) are suitable for multiple cycles of mechanical lithography and topography mapping of produced patterns. The double-layer resist is developed based on $\mathrm{As}_{40} \mathrm{Se}_{60} / \mathrm{As}_{4} \mathrm{Ge}_{30} \mathrm{~S}_{66}$ chalcogenide compounds. The effectiveness of the resist for mechanical SPL is illustrated by prototyping the masks containing features of several tens of nanometers in size. The problem of pile-ups solved using a thin $(5 \ldots 10 \mathrm{~nm})$ top layer of the $\mathrm{As}_{40} \mathrm{Se}_{60}$ resist. In the case of $2 \mathrm{D}$ materials drop-casted from an aqueous suspension, in particular, flakes of graphene oxide, their weak fixation on the surface, the presence of folded wrinkles, a high modulus of elasticity and a fracture strength could be taken into account. The multilayered GO flakes of $10 \ldots 20 \mathrm{~nm}$ thickness could be mechanically modified in a similar manner like chalcogenide resists. But the loading force should be increased by several times to reach a plastic deformation of GO. The GO fracture process is inhomogeneous and illustrates a threshold behavior of tip penetration into material at an increasing force. The load of $4 \ldots 9 \mu \mathrm{N}$ is sufficient for the $\mathrm{As}_{40} \mathrm{Se}_{60}$ engraving in the used configuration. The indentation and cutting the GO flakes require forces of $12 \ldots 18 \mu \mathrm{N}$. To fix $\mathrm{GO}$ flakes on the surface and to form contact with metal electrodes, the "riveting"/"smoothing" of flakes by AFM tip could be recommended. The developed extensions of the NanoScript ${ }^{\mathrm{TM}}$ software functionality allow a quick transformation of vector and bitmap images into the software code for surface engraving by the mechanical SPL. The developed software and methodical support of mechanical nanolithography could be used in laboratory prototyping the device structures for bio/nanosensorics, plasmonics, 2D electronics, etc. 


\section{Acknowledgement}

This work was partially supported by National Academy of Sciences of Ukraine with the projects $27 / 18 \mathrm{H}$ and DP 3.5.4.8.

\section{References}

1. Binnig G., Rohrer H., Gerber C., Weibel E. Surface studies by scanning tunneling microscopy. Phys. Rev. Lett. 1982. 49. P. 57.

2. Binnig G., Quate C.F., Gerber C. Atomic force microscope. Phys.Rev. Lett. 1986. 56. P. 930.

3. Marrian C., Dobisz E. High-resolution lithography with a vacuum STM. Ultramicroscopy. 1992. 42. P. 1309-1316.

4. Sohn L., Willett R. Fabrication of nanostructures using atomic force microscope based lithography. Appl. Phys. Lett. 1995. 67. P. 1552-1554.

5. Bouchiat V., Esteve D. Lift-off lithography using an atomic force microscope. Appl. Phys. Lett. 1996. 69. P. 3098-3100.

6. Lytvyn P., Olikh O., Lytvyn O., Dyachyns'ka O., Prokopenko I. Ultrasonic assisted nanomanipulations with atomic force microscope. Semiconductor Physics, Quantum Electronics \& Optoelectronics. 2010. 13. P. 36-42.

7. Lytvyn P.M., Efremov A.A., Lytvyn O.S., Prokopenko I.V., Mazur Y.I., Ware M.E., Fologia D., Salamo G.J. Precise manipulations with asymmetric nano-objects viscoelastically bound to a surface. J. Nano Res. 2016. 39. P. 256.

8. O'Connell C., Higgins M.J., Moulton S.E., Wallace G.G. Nano-bioelectronics via dip-pen nanolithography. J. Mater. Chem. C. 2015. 3. P. 6431-6444.

9. Liu H., Hoeppener S., Schubert U.S. Nanoscale materials patterning by local electrochemical lithography. Adv. Eng. Mater. 2016. 18. P. 890902.

10. Gottlieb S., Lorenzoni M., Evangelio L., FernándezRegúlez M., Ryu Y., Rawlings C., Spieser M., Knoll A., Perez-Murano F. Corrigendum: Thermal scanning probe lithography for the directed selfassembly of block copolymers. Nanotechnology. 2017. 28. 289501.

11. Dago A.I., Ryu Y.K., Garcia R. Sub-20 nm patterning of thin layer $\mathrm{WSe}_{2}$ by scanning probe lithography. Appl. Phys. Lett. 2016. 109. P. 163103.

12. Ryu Y.K., Garcia R. Advanced oxidation scanning probe lithography. Nanotechnology. 2017. 28. P. 142003 .

13. Albisetti E., Petti D., Pancaldi M., Madami M., Tacchi S., Curtis J., King W., Papp A., Csaba G., Porod W. Nanopatterning reconfigurable magnetic landscapes via thermally assisted scanning probe lithography. Nature Nanotechnology. 2016. 11. P. 545.

14. Soh H.T., Guarini K.W., Quate C.F. Scanning Probe Lithography. Springer Science \& Business Media, 2013.
15. Garcia R., Knoll A.W., Riedo E. Advanced scanning probe lithography. Nature Nanotechnology. 2014. 9. P. 577.

16. Liu X., Chen K.S., Wells S.A., Balla I., Zhu J., Wood J.D., Hersam M.C. Scanning probe nanopatterning and layer-by-layer thinning of black phosphorus. Adv. Mater. 2017. 29, No 1. 1604121.

17. Vasić B., Kratzer M., Matković A., Nevosad A., Ralević U., Jovanović D., Ganser C., Teichert C., Gajić R. Atomic force microscopy based manipulation of graphene using dynamic plowing lithography. Nanotechnology. 2012. 24. P. 015303.

18. Lee W.-K., Tsoi S., Whitener K.E., Stine R., Robinson J.T., Tobin J.S., Weerasinghe A., Sheehan P.E., Lyuksyutov S.F. Robust reduction of graphene fluoride using an electrostatically biased scanning probe. Nano Res. 2013. 6. P. 767-774.

19. Wei Z., Wang D., Kim S., Kim S.-Y., Hu Y., Yakes M.K., Laracuente A.R., Dai Z., Marder S.R., Berger C. Nanoscale tunable reduction of graphene oxide for graphene electronics. Science. 2010. 328. P. 1373-1376.

20. Zhao J., Swartz L.A., Lin W.-F., Schlenoff P.S., Frommer J., Schlenoff J.B., Liu G.-Y. Threedimensional nanoprinting via scanning probe lithography-delivered layer-by-layer deposition. ACS Nano. 2016. 10. P. 5656-5662.

21. Liu X., Carbonell C., Braunschweig A.B. Towards scanning probe lithography-based 4D nanoprinting by advancing surface chemistry, nanopatterning strategies, and characterization protocols. Chem. Soc. Rev. 2016. 45. P. 6289-6310.

22. Lytvyn P., Lytvyn O., Dyachyns'ka O., Grytsenko K., Schrader S., Prokopenko I. Mechanical scanning probe nanolithography: Modeling and application. Semiconductor Physics, Quantum Electronics \& Optoelectronics. 2012. 15. P. 321-327.

23. Lee C.W., Min B.J., Kim S.I., Jeong H.K. Stacking of water molecules in hydrophilic graphene oxides characterized by Kelvin probe force microscopy. Carbon. 2013. 54. P. 353-358.

24. Prezioso S., Perrozzi F., Giancaterini L., Cantalini C., Treossi E., Palermo V., Nardone M., Santucci S., Ottaviano L. Graphene oxide as a practical solution to high sensitivity gas sensing. J. Phys. Chem. C. 2013. 117. P. 10683-10690.

25. Trunov M., Lytvyn P., Dyachyns'ka O. Alternating matter motion in photoinduced mass transport driven and enhanced by light polarization in amorphous chalcogenide films. Appl. Phys. Lett. 2010. 97. P. 031905.

26. Trunov M., Cserhati C., Lytvyn P., Kaganovskii Y., Kökényesi S. Electron beam-induced mass transport in As-Se thin films: compositional dependence and glass network topological effects. J. Phys. D: Appl. Phys. 2013. 46. P. 245303.

27. Trunov M., Lytvyn P., Nagy P., Csik A., Rubish V., Kökényesi S. Light-induced mass transport in amorphous chalcogenides: Toward surface plasmon-assisted nanolithography and near-field 
nanoimaging. phys. status solidi (b). 2014. 251. P. 1354-1362.

28. Dan'ko V., Dmitruk M., Indutnyi I., Mamykin S., Myn'ko V., Shepeliavyi P., Lukaniuk M., Lytvyn P. $\mathrm{Au}$ gratings fabricated by interference lithography for experimental study of localized and propagating surface plasmons. Nanoscale Res. Lett. 2017. 12. P. 190.

29. Fitzgerald C., Fukunaga L. NanoLithography Support Note 316, 2001.

30. TESP AFM tips, Bruker.

31. Hummers W.S. Jr, Offeman R.E. Preparation of graphitic oxide. J. Amer. Chem. Soc. 1958. 80. P. 1339-1339.

32. Chen J., Yao B., Li C., Shi G. An improved Hummers method for eco-friendly synthesis of graphene oxide. Carbon. 2013. 64. P. 225-229.

33. Dan'ko V., Indutnyi I., Min'ko V., Shepelyavyi P. Interference photolithography with the use of resists on the basis of chalcogenide glassy semiconductors. Optoelectronics, Instrumentation and Data Processing. 2010. 46. P. 483-490.

34. Oliver W.C., Pharr G.M. Measurement of hardness and elastic modulus by instrumented indentation: Advances in understanding and refinements to methodology. J. Mater. Res. 2004. 19. P. 3-20.

35. Clifford C.A., Seah M.P. Quantification issues in the identification of nanoscale regions of homopolymers using modulus measurement via AFM nanoindentation. Appl. Surf. Sci. 2005. 252. P. 1915-1933.

36. Atanassova E., Lytvyn P., Dub S., Konakova R., Mitin V., Spassov D. Nanomechanical properties of pure and doped $\mathrm{Ta}_{2} \mathrm{O}_{5}$ and the effect of microwave irradiation. J. Phys. D: Appl. Phys. 2012. 45. P. 475304.

37. Trunov M., Dub S., Shmegera R. Photo-induced transition from elastic to plastic behavior in amorphous As-Se films studied by nanoindentation. J. Optoelectron. Adv. Mater. 2005. 7. P. 619-624.

38. Suk J.W., Piner R.D., An J., Ruoff R.S. Mechanical properties of monolayer graphene oxide. ACS Nano. 2010. 4. P. 6557-6564.

\section{Authors and CV}

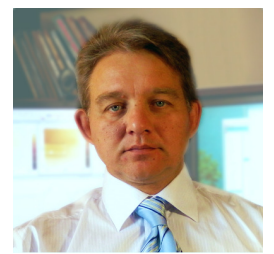

Lytvyn P.M. PhD in Physics and Mathematics, Senior Researcher of the Laboratory of Electron probe methods for structural and elemental analysis of semiconductor materials and systems, V. Lashkaryov Institute

of Semiconductor Physics, NAS of Ukraine. The area of scientific interests covers nanophysics of semiconductors and related materials.

V. Lashkaryov Institute of Semiconductor Physics, NAS of Ukraine

E-mail:plyt@isp.kiev.ua

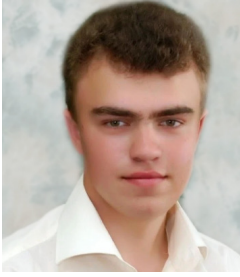

Malyuta S.V. Magister student at the Microelectronics department of National Technical University of Ukraine "Igor Sikorsky Kyiv Polytechnic Institute". The area of scientific interests includes scanning probe microscopy.

National Technical University of Ukraine "Igor Sikorsky Kyiv Polytechnic Institute"

E-mail: serhiy.malyuta@gmail.com

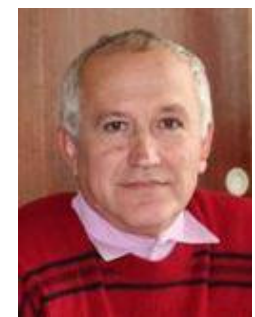

Indutnyi I.Z. Professor, Doctor of Sciences in Physics and Mathematics, leading researcher at Department of Photochemical Phenomena in semiconductors, V. Lashkaryov Institute of Semiconductor Physics, NAS of Ukraine. The area of scientific interests covers optics of thin films, physics of nanoparticles and nanostructures, photostimulated processes in solids and on surfaces.

$V$. Lashkaryov Institute of Semiconductor Physics, NAS of Ukraine

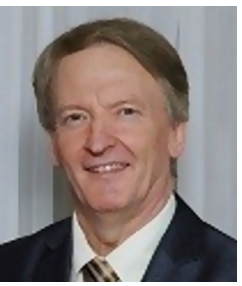

Efremov A.A.: PhD in Physics and Mathematics, Senior Researcher of the Laboratory of Electron probe methods of structural and elemental analysis of semiconductor materials and systems, V. Lashkaryov Institute of Semiconductor Physics, NAS of Ukraine. The area of scientific interests covers computer simulations in diagnostics, formation, and modifications of different kinds of nanostructures.

V. Lashkaryov Institute of Semiconductor Physics, NAS of Ukraine

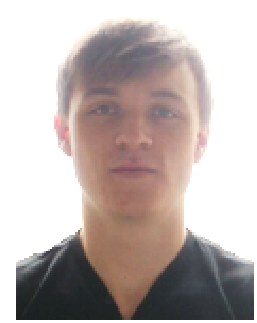

Slobodian O.V. PhD student at the Physics and Mathematics department of National Technical University of Ukraine "Igor Sikorsky Kyiv Polytechnic Institute". The area of scientific interests includes investigation of electrical and optical properties of ultrathin carbon films.

National Technical University of Ukraine "Igor Sikorsky Kyiv Polytechnic Institute"

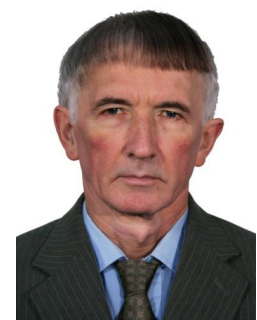

Minko V.I. PhD in Physics and Mathematics, Senior Researcher at Department of Photochemical Phenomena in semiconductors, V. Lashkaryov Institute of Semiconductor Physics, NAS of Ukraine. The area of scientific interests covers interference lithography, holography, inorganic photoresists.

V. Lashkaryov Institute of Semiconductor Physics, NAS of Ukraine 


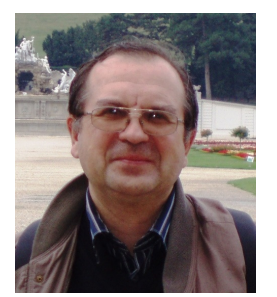

Nazarov A.N. Doctor of Sciences in Physics and Mathematics, Head of department of the Functional Materials and Nanostructures, V. Lashkaryov Institute of Semiconductor Physics, NAS of Ukraine, Professor of department of General Physics and Solid State Physics, National Technical University of Ukraine "Igor Sikorsky KPI". The area of scientific interests of Dr. Nazarov includes physics, technology and characterization of nanoscaled carbon based materials and devices, SOI structures and devices, radiation effects in carbon and silicon based materials, structures and devices.

V. Lashkaryov Institute of Semiconductor Physics, NAS of Ukraine

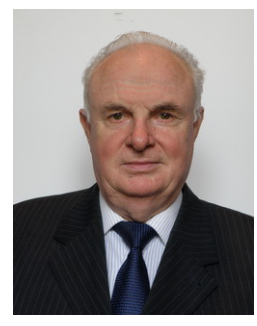

Borysov O.V. Professor, $\mathrm{PhD}$ in Technical Sciences at the Microelectronics department of National Technical University of Ukraine "Igor Sikorsky Kyiv Polytechnic Institute". The area of scientific interests includes nonlinear phenomena in dielectrics.

National Technical University of Ukraine "Igor Sikorsky Kyiv Polytechnic Institute"

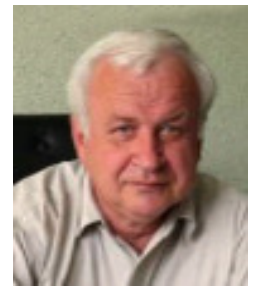

Prokopenko I.V. Professor, Doctor of Sciences in Physics and Mathematics, Head of the Laboratory of Electron probe methods of structural and elemental analysis of semiconductor materials and systems, V. Lashkaryov Institute of Semiconductor Physics, NAS of Ukraine. The area of scientific interests covers semiconductor material science.

V. Lashkaryov Institute of Semiconductor Physics, NAS of Ukraine. 